Check for updates

Cite this: Chem. Sci., 2020, 11, 126

๑ All publication charges for this article have been paid for by the Royal Society of Chemistry

Received 13th August 2019

Accepted 27th October 2019

DOI: $10.1039 / \mathrm{c9sc04053f}$

rsc.li/chemical-science

\section{Dimeric boroles: effective sources of monomeric boroles for heterocycle synthesis $\uparrow$}

\author{
Xiaojun Su, (D) J. J. Baker and Caleb D. Martin (D)*
}

Monomeric boroles have been gaining attention as reagents for the synthesis of heterocycles due to their ability to insert atoms into the $\mathrm{BC}_{4}$ ring in a single step. Although unique boron frameworks can be accessed via this methodology, the products feature aryl substitution on the carbon centers as steric bulk is required to preclude borole dimerization. This work demonstrates that insertion chemistry is possible with DielsAlder dimeric boroles and that such reactivity is not exclusive to monomeric boroles with bulky groups. With 1-phenyl-2,3,4,5-tetramethylborole dimer, the formal 1,1-insertion of a nitrene and sulfur generate the six-membered aromatic 1,2-azaborine and 1,2-thiaborine, respectively. The isolation of the 1,2thiaborine enabled the synthesis of an $\eta^{6}$-chromium complex. Benzophenone and diphenylketene readily insert a $\mathrm{CO}$ unit to generate $\mathrm{BOC}_{5}$ seven-membered rings confirming dimeric boroles can serve as monomeric synthons in 1,2-insertion reactions. An epoxide did not furnish the anticipated eightmembered $\mathrm{BOC}_{6}$ ring, instead provided a bicyclic system with a $\mathrm{BOC}_{3}$ ring. The insertion chemistry was demonstrated with two other borole dimers featuring different substitution with diphenylketene as a substrate. This work elevates borole insertion chemistry to a new level to access products that do not require bulky substitution.
Boroles are reactive $\mathrm{BC}_{4}$ heterocycles that feature a threecoordinate boron center linking a 1,3-butadiene backbone first disclosed by Eisch in his seminal report in $1969 .^{1}$ The four $\pi$-electron ring results in an anti-aromatic species high in thermodynamic energy making boroles attractive reagents for more stable species. Within the central ring, the boron center is highly Lewis acidic, the $\mathrm{BC}_{4}$ ring can be reduced, and the diene engages in Diels-Alder reactions. ${ }^{2-4}$ It has been demonstrated that Lewis acid-base adducts can rearrange if a reactive functionality is pendent on the Lewis base (e.g. imine, nitrile) to access ring expanded products. ${ }^{2 c}$ This is particularly significant as boron heterocycles are in small molecule drugs ${ }^{5}$ and are being investigated in electronic materials. ${ }^{6}$ Despite this interest, accessing heterocycles containing tricoordinate boron centers is challenging due to the propensity of boron reagents to react with nucleophiles to form four-coordinate species.

Boroles can be accessed through three general routes, one being the direct salt metathesis with a substituted 1,4-dilithio1,3-butadiene and dihaloborane or organotrifluoroborate. ${ }^{2 d, 7}$ Borolide dianions can undergo a two electron oxidation to the neutral boroles and the third method is transmetallation from tin or zirconium precursors. ${ }^{3,8}$ The transmetallation route is the

Department of Chemistry and Biochemistry, Baylor University, One Bear Place \#97348, Waco, TX 76798, USA. E-mail: caleb_d_martin@baylor.edu

$\dagger$ Electronic supplementary information (ESI) available. CCDC 1942996-1943000 and 1960237-1960239. For ESI and crystallographic data in CIF or other electronic format see DOI: $10.1039 / \mathrm{c} 9 \mathrm{sc} 04053 \mathrm{f}$ most popular method due to the ease in manipulating the precursors including compatibility with non-coordinating solvents that enable the isolation of tricoordinate species. ${ }^{8 b}$

Although boroles have been effective reagents for the preparation of ring systems of six to eight atoms, ${ }^{2 c, 9}$ a major limitation has been the bulk on the boroles required to kinetically preclude dimerization (e.g. A, Fig. 1). ${ }^{\mathbf{1 1 0}}$ Boroles bearing a halide on boron (e.g. B) undergo complex decomposition at low temperatures ${ }^{11}$ while those with organic groups dimerize via $[4+$ 2] cycloaddition with one equivalent acting as the diene and the other as the dienophile $\left(\right.$ e.g. $\left.\mathbf{C}_{2}\right){ }^{3,12}$ The latter process is dictated by bulk on the carbon centers and is reminiscent of the dimerization of cyclopentadiene. In contrast to cyclopentadiene, the monomers are not isolable, however, reactivity studies suggest that the retro Diels-Alder process can be thermally induced. ${ }^{3,13}$ Despite these dimers being known since 1985 , the only studies have been heating the dimers in the presence of metal precursors to access $\eta^{5}$-metal complexes ${ }^{\mathbf{1 4}}$ or examining their Diels-Alder reactivity., ${ }^{3,13}$ If dimeric boroles could be utilized as reagents for ring expansion reactions, it would circumvent the requirement of bulky substituted monomeric boroles enabling access to a diverse library of products. We herein investigate the ability of Diels-Alder dimeric boroles to serve as sources of monomers in ring expansion reactions.

A particularly appealing class of molecules are hybrid inorganic/organic analogues of benzene in which a $\mathrm{C}=\mathrm{C}$ unit is replaced by boron and lone pair bearing heteroatom. ${ }^{15}$ Pentaarylboroles have been effective in their preparation by 1,1-insertion 


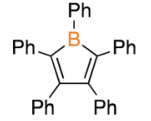

A

Bulky Substitution Monomeric Boroles
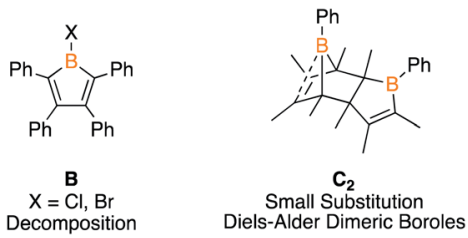

Fig. 1 Examples of boroles and a summary of their stability.

reactions but result in products with five bulky groups. ${ }^{16} \mathrm{We}$ envisioned that a dimeric borole, 1-phenyl-2,3,4,5tetramethylborole dimer $\mathbf{C}_{2}$, may also be an effective synthon of its monomer $\mathbf{C}$ to generate six-membered heteroaromatic targets. To target 1,2-azaborines, a 2 : 1 stoichiometric mixture of phenyl azide with dimer $\mathbf{C}_{2}$ in toluene was heated to $100{ }^{\circ} \mathrm{C}$ and monitored by in situ ${ }^{11} \mathrm{~B}$ NMR spectroscopy (Scheme 1). The consumption of $\mathbf{C}_{\mathbf{2}}$ was observed after $12 \mathrm{~h}$ by the disappearance of the peaks at -6.3 and 69.8 ppm coupled with the emergence of a new peak at $35.5 \mathrm{ppm}$, representative of 1,2-azaborine species. ${ }^{16 d-g}$ The identity of the insertion product was confirmed by a single crystal X-ray diffraction study (Fig. 2) and upon workup, the product was isolated as a yellow powder in $70 \%$ yield. ${ }^{1} \mathrm{H}$ NMR spectroscopy of the solid redissolved in $\mathrm{CDCl}_{3}$ indicated a simplified methyl region with four signals integrating in equivalent ratios in contrast to eight signals for dimer $\mathbf{C}_{2}$. 1,2Azaborines are gaining attention for utility in materials and medicinal chemistry and this reaction demonstrates an efficient manner to access these heterocycles in a single step.

To determine if $\mathbf{C}_{2}$ is capable of acting as a source of $\mathbf{C}$ in other 1,1-insertion reactions it was reacted with excess elemental sulfur in toluene. ${ }^{17}$ Monitoring the reaction by in situ ${ }^{11} \mathrm{~B}$ NMR spectroscopy indicated that upon heating to $100{ }^{\circ} \mathrm{C}$ for $24 \mathrm{~h}$ a major peak at $49.8 \mathrm{ppm}$ emerged, which lies in the range of reported 1,2-thiaborines (35.8-51.1 ppm). ${ }^{15 f, 16 c, 18}$ Upon workup, a yellow oil was isolated in $49 \%$ yield. The liquid state at room temperature prevented obtaining a solid state structure. Since 1,2-thiaborines are a six- $\pi$-electron aromatic system, we postulated that the $\pi$-system could coordinate to a transition metal. A suite of 1,2-azaborine metal complexes have been prepared, ${ }^{19}$ but there is not an example of a 1,2-thiaborine complex in the literature, or any chalcogenaborine metal complexes. ${ }^{15 e, 15 f, 20}$ Our attempts to prepare a 1,2-thiaborine chromium complex from $\mathrm{Cr}(\mathrm{CO})_{3}\left(\mathrm{CH}_{3} \mathrm{CN}\right)_{3}$ and pentaaryl 1,2thiaborines derived from monomeric pentaarylboroles were

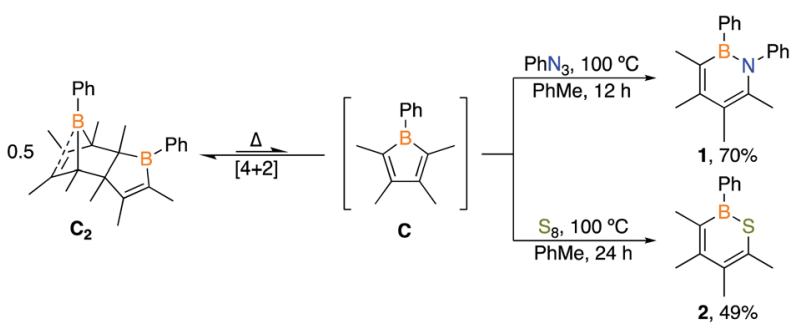

Scheme 1 Reactions of borole dimer $C_{2}$ with phenyl azide and elemental sulfur.
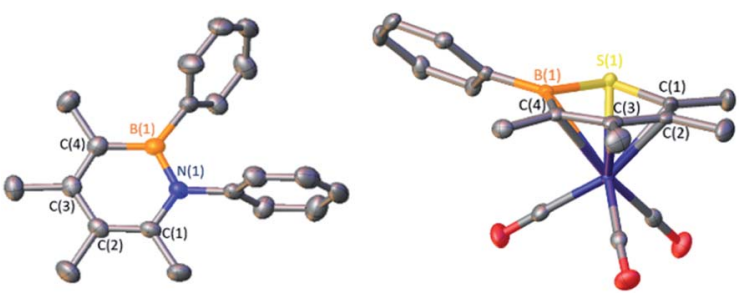

Fig. 2 Solid-state structures of 1 (left) and $2 \cdot \mathrm{Cr}(\mathrm{CO})_{3}$ (right). Hydrogen atoms are omitted for clarity and ellipsoids are depicted at the 50\% probability level. Selected bond lengths (Å) for 1 : B(1)-N(1) 1.443(4), $N(1)-C(1) 1.399(4), C(1)-C(2) 1.370(4), C(2)-C(3) 1.442(5), C(3)-C(4)$ 1.377(5), $C(4)-B(1) 1.513(4)$; for $2 \cdot C r(C O)_{3}: B(1)-S(1) 1.828(2), S(1)-C(1)$ 1.757(3), $C(1)-C(2) 1.397(3), C(2)-C(3) 1.441(3), C(3)-C(4) 1.416(4)$, $\mathrm{B}(1)-\mathrm{C}(4)$ 1.515(3), $\mathrm{B}(1)-\mathrm{Cr} 2.388(3), \mathrm{S}(1)-\mathrm{Cr} 2.4367(6), \mathrm{C}(1)-\mathrm{Cr}$ 2.175(2), C(2)-Cr 2.223(3), C(3)-Cr 2.251(3), C(4)-Cr 2.273(2).

unsuccessful, presumably due to the bulky substituents which has also been reported in attempts to coordinate metals to the central ring of hexaphenylbenzene. ${ }^{21}$ To determine if the smaller 1,2-thiaborine could act as a ligand, the reaction of excess $\mathrm{Cr}(\mathrm{CO})_{3}\left(\mathrm{CH}_{3} \mathrm{CN}\right)_{3}$ with 1,2-thiaborine (2) was conducted in THF at $23{ }^{\circ} \mathrm{C}$ and in situ monitoring by ${ }^{11} \mathrm{~B}$ NMR spectroscopy revealed an upfield shift from free 2 at $49.8 \mathrm{ppm}$ to $29.1 \mathrm{ppm}$ with the reaction complete after $24 \mathrm{~h}$ (Scheme 2). The resonance is consistent with $\eta^{6}$-bound 1,2-azaborine metal complexes. ${ }^{19} \mathrm{~A}$ single ${ }^{13} \mathrm{C}\left\{{ }^{1} \mathrm{H}\right\}$ NMR shift at 229.83 ppm was detected for the three carbonyl groups indicating chemical equivalency on the NMR timescale, attributed to rapid rotation about the $\mathrm{BSC}_{4}$ ring. Upon work up a red solid was isolated in $76 \%$ yield and an $\mathrm{X}$-ray diffraction study gratifyingly confirmed the product as the half-sandwich tricarbonylchromium complex $\quad 2 \cdot \mathbf{C r}(\mathbf{C O})_{3}$ (Fig. 2).

The solid state structure of $\mathbf{2} \cdot \mathbf{C r}(\mathbf{C O})_{3}$ confirms $\eta^{6}$-coordination to chromium with a planar ring (max. deviation from planarity $=0.04 \AA$ ), although the chromium bonds to boron $[\mathrm{Cr}-\mathrm{B}=2.388(3) \AA]$ and sulfur $[\mathrm{Cr}-\mathrm{S}=2.4367(6) \AA]$ are longer than those to the four carbon atoms [B-C range 2.175(2)2.273(2) $\AA$ ] . The bond lengths within the 1,2-thiaborine ring of $2 \cdot \mathbf{C r}(\mathbf{C O})_{3}$ are marginally longer in comparison to the only nondisordered uncomplexed 1,2-thiaborine, which is expected upon coordination. ${ }^{\mathbf{1 6 c}}$ The carbonyl stretching frequencies are a gauge of the donor properties of aromatic ligands. ${ }^{22}$ FT-IR spectroscopy revealed C-O stretching frequencies of 1964, 1908 and $1873 \mathrm{~cm}^{-1}$ for $\mathbf{2} \cdot \mathbf{C r}(\mathbf{C O})_{3}$ which are lower than those of the chromium complex with 1,2-dihydro-1-methyl-2-phenyl-1,2azaborine $\left(1979,1916,1900 \mathrm{~cm}^{-1}\right) .{ }^{19 a}$ This indicates that $1,2-$ thiaborine 2 induces more $\pi$-backbonding to the CO ligands by enriching the electron density at chromium more than the 1,2azaborine.

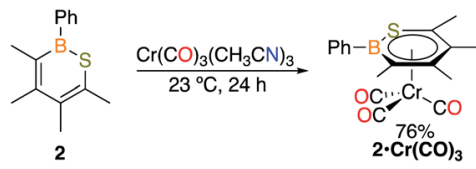

Scheme 2 Reaction of 1,2-thiaborine 2 with $\mathrm{Cr}\left(\mathrm{CH}_{3} \mathrm{CN}\right)_{3}(\mathrm{CO})_{3}$. 


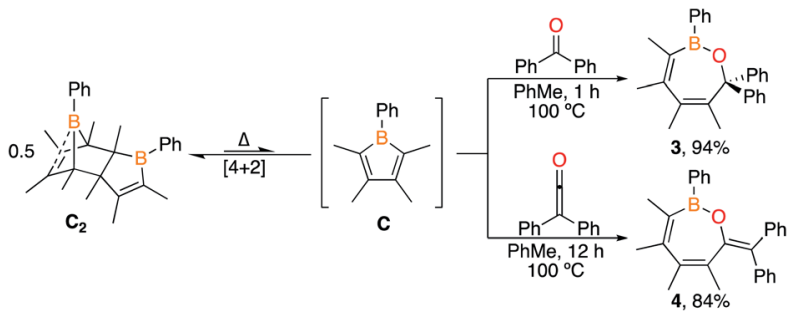

Scheme 3 Reaction of dimer $\mathrm{C}_{2}$ with benzophenone and diphenylketene.

The resiliency of the $\pi$-coordination of the 1,2-thiaborine to chromium was investigated. No decomposition or migration to the B-phenyl group was observed at room temperature. Heating a THF- $d_{8}$ solution of $2 \cdot \mathbf{C r}(\mathbf{C O})_{3}$ resulted in free 2 by ${ }^{1} \mathrm{H}$ NMR spectroscopy and an insoluble grey precipitate, indicating slow decomposition of $\mathbf{2} \cdot \mathbf{C r}(\mathbf{C O})_{3}$ with no evidence of migration of the chromium center. Adding excess benzene as an extraneous $\pi$-donor into a solution of $2 \cdot \mathbf{C r}(\mathbf{C O})_{3}$ in THF- $d_{8}$ did not result in any reaction at room temperature. During the course of heating, in situ ${ }^{1} \mathrm{H}$ NMR spectroscopy revealed that $2 \cdot \mathbf{C r}(\mathbf{C O})_{3}$ decomposed by generating (benzene)chromium tricarbonyl, free 2, and a similar grey precipitate. Attempts to access $\eta^{1}$-coordination chemistry via the sulfur atom in 2 were unsuccessful due to the relatively weak sulfur donor (see $\mathrm{ESI} \dagger$ ).

To examine the ability of borole synthon $\mathbf{C}_{2}$ to undergo 1,2insertions to access seven-membered rings, the 1:2 stoichiometric reactions of $\mathbf{C}_{\mathbf{2}}$ with benzophenone and diphenylketene in toluene- $d_{8}$ at room temperature were investigated. No reaction occurred at room temperature but upon heating the solutions to $100{ }^{\circ} \mathrm{C}$ ( $1 \mathrm{~h}$ for benzophenone and $12 \mathrm{~h}$ for diphenylketene), ${ }^{1} \mathrm{H}$ NMR spectroscopy revealed consumption of dimer $\mathbf{C}_{2}$, corroborated by ${ }^{11} \mathrm{~B}$ NMR spectroscopy with new resonances at $43.6 \mathrm{ppm}$ for benzophenone and 43.2 ppm for diphenylketene (Scheme 3). Both are consistent with a three-coordinate boron bound to an oxygen. ${ }^{9 \boldsymbol{e}, 16 \boldsymbol{b}}$ Single crystals grown for X-ray diffraction studies identified the products as the seven-membered $\mathrm{BOC}_{5}$ rings 3 and 4 in which the 1,2-dipolar CO unit is inserted into the endocyclic B-C bond of the monomeric borole (Fig. 3). Both species adopt boat-like conformations.
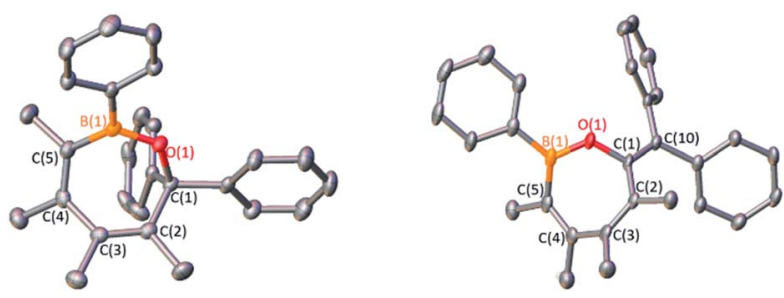

Fig. 3 (a) Solid-state structure of 3 (left) and 4 (right) hydrogen atoms are omitted for clarity and ellipsoids are depicted at the $50 \%$ probability level. Selected bond lengths (Å) for 3: $B(1)-O(1) 1.366(5), O(1)-C(1)$ 1.452(5), $C(1)-C(2) 1.542(5), C(2)-C(3) 1.348(5), C(3)-C(4) 1.486(5)$, $C(4)-C(5) 1.347(5), C(5)-B(1) 1.563(5)$; for 4 : $B(1)-O(1) 1.368(2), O(1)-$ $C(1)$ 1.392(3), $C(1)-C(2)$ 1.484(2), $C(2)-C(3)$ 1.346(2), $C(3)-C(4)$ 1.489(2), $C(4)-C(5) 1.353(3), C(5)-B(1) 1.558(3), C(1)-C(10) 1.345(3)$.
1,1-Diphenylethylene oxide reacts with pentaphenylborole to generate a rare eight-membered boron heterocycle from the insertion of the $\mathrm{C}_{2} \mathrm{O}$ unit. ${ }^{9 a}$ In the reaction of two equivalents of 1,1-diphenylethylene oxide with $\mathbf{C}_{2}$ at $100{ }^{\circ} \mathrm{C}$ in toluene, in situ ${ }^{11} \mathrm{~B}$ NMR spectroscopy revealed the complete consumption of $\mathbf{C}_{2}$ after $14 \mathrm{~h}$ and a new signal at $59.4 \mathrm{ppm}$, differing from the eight-membered boracycle in the corresponding reaction with pentaphenylborole (46.3 ppm). ${ }^{9 a}$ Single crystal X-ray diffraction identified the product as a bicyclic compound composed of fused $\mathrm{BC}_{4}$ and $\mathrm{BOC}_{3}$ rings (5, Fig. 4) with a boron and carbon atom at the ring junctions. The boron center is essentially trigonal planar with the sum of angles about boron being $358.0(6)^{\circ}$. The presence of the phenyl group on the carbon adjacent to boron, $\mathrm{C}(6)$, suggests a rearrangement occurred. The $\mathrm{B}(1)-\mathrm{O}(1)$ bond $[1.353(3) \AA]$ is consistent with a $\mathrm{B}-\mathrm{O}$ single bond. ${ }^{9 a, 23}$ The carbon-carbon bond lengths in the $\mathrm{BC}_{4}$ ring derived from the borole alternate $[\mathrm{C}(3)-\mathrm{C}(4)=1.530(3), \mathrm{C}(4)-$ $\mathrm{C}(5)=1.342(4), \mathrm{C}(5)-\mathrm{C}(6)=1.546(3) \AA]$ which is consistent with 1-bora-cyclopent-3-ene ring systems. ${ }^{9 \boldsymbol{d}, \mathbf{2 4}} \mathrm{BOC}_{3}$ rings with a fused ring have been gaining attention with the effective drugs Kerydin ${ }^{\circledR}$ (onychomycosis) and Eucrisa ${ }^{\circledR}$ (eczema) containing such bicyclic systems. ${ }^{5 d, 5 e}$

A proposed mechanism can be drawn that proceeds through an initial Lewis acid-base adduct Int1 (Scheme 4). The epoxide ring opens via the oxygen-carbon bond of the diphenyl carbon to furnish the resonance stabilized carbocation Int2. The diene attacks the carbocation to forge the bicyclic framework and the a)

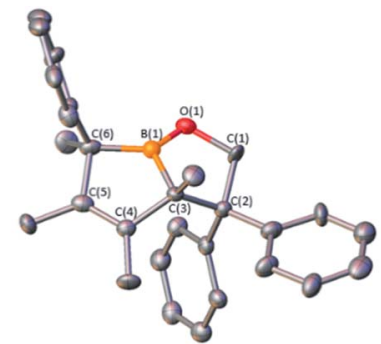

b)

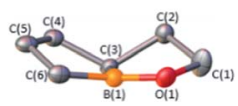

Fig. 4 (a) Solid-state structure of 5. Hydrogen atoms are omitted for clarity and ellipsoids are depicted at the $50 \%$ probability level. Selected bond lengths $(A)$ : $B(1)-O(1)$ 1.353(3), O(1)-C(1) 1.460(3), C(1)-C(2) 1.567(3), $C(2)-C(3) 1.609(3), C(3)-C(4) 1.530(3), C(4)-C(5) 1.342(4)$, $C(5)-C(6) 1.546(3), C(6)-B(1)$ 1.582(4), B(1)-C(3) 1.565(4); (b) View of the fused bicyclic core along the boron plane.

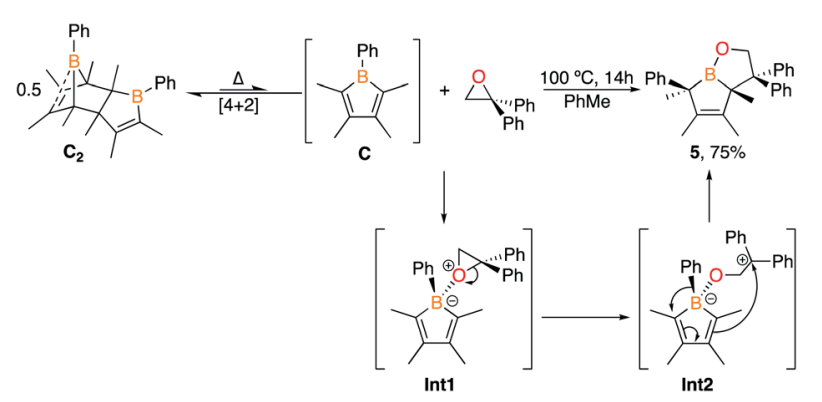

Scheme 4 Reaction of 1,1-diphenylethylene oxide with $C_{2}$ and proposed mechanism. 


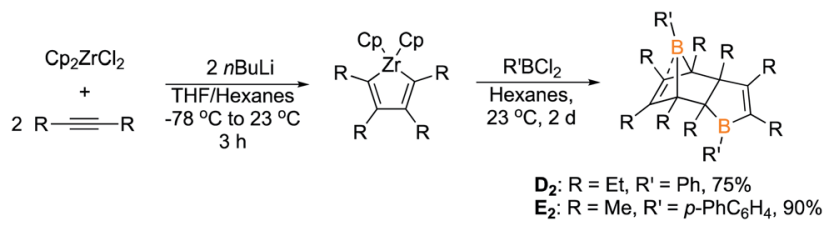

Scheme 5 Synthesis of borole dimers $D_{2}$ and $E_{2}$.

phenyl group migrates to the adjacent carbon to give $\mathbf{5}$. The migration occurs on the same face rationalizing the antistereochemistry of the methyl groups observed in the solid state structure. The centrosymmetric $P 2_{1} / n$ space group indicates that both enantiomers are generated. This differs from the pentaphenylborole product in which the endocyclic B-C bond of the borole attacks the carbocation in Int2 to generate an eight-membered ring. ${ }^{9 a, 25}$ Although this bicyclic framework has not been observed previously in a product from a borole reaction, it has been proposed as an intermediate in insertion reactions and may provide insight into other reaction mechanisms. ${ }^{16 e, 26}$

To determine if other Diels-Alder dimeric boroles are capable of generating insertion products, two other Diels-Alder borole dimers, 1-phenyl-2,3,4,5-tetraethylborole dimer $\left(\mathbf{D}_{2}\right)$ and 1-biphenyl-2,3,4,5-tetramethylborole dimer $\left(\mathbf{E}_{2}\right)$, were prepared via transmetallation of zirconium precursors (Scheme 5). The identity of the tetraethyl dimer $\mathbf{D}_{2}$ was established by obtaining

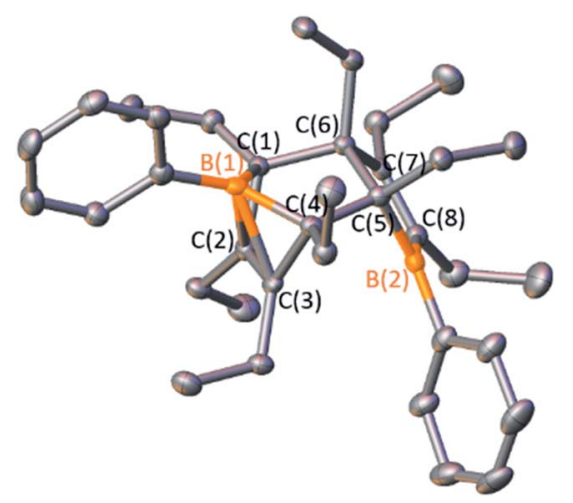

Fig. 5 Solid-state structure of $D_{2}$. Hydrogen atoms are omitted for clarity and ellipsoids are depicted at the $50 \%$ probability level. Selected bond lengths $(\AA)$ for $D_{2}$ : $B(1)-C(1) 1.619(4), B(1)-C(4) 1.611(4), C(1)-C(2)$ 1.514(4), $C(2)-C(3) 1.380(4), C(3)-C(4) 1.524(4), C(4)-C(5) 1.585(3)$, $C(5)-C(6) 1.573(4), C(6)-C(7) 1.527(4), C(7)-C(8) 1.357(4), B(2)-C(5)$ $1.599(5), B(2)-C(8) 1.540(4)$.

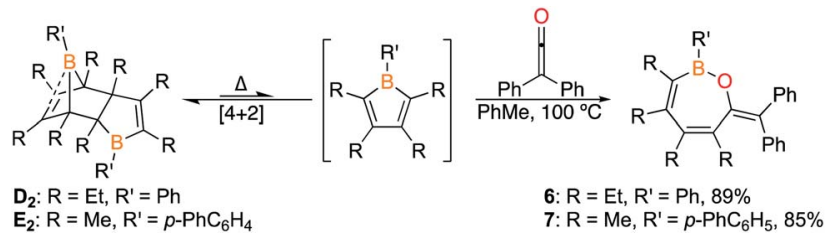

Scheme 6 Reaction of diphenylketene with $D_{2}$ and $E_{2}$. Reaction times: $1 \mathrm{~h}$ for 6 and $8 \mathrm{~h}$ for 7 .
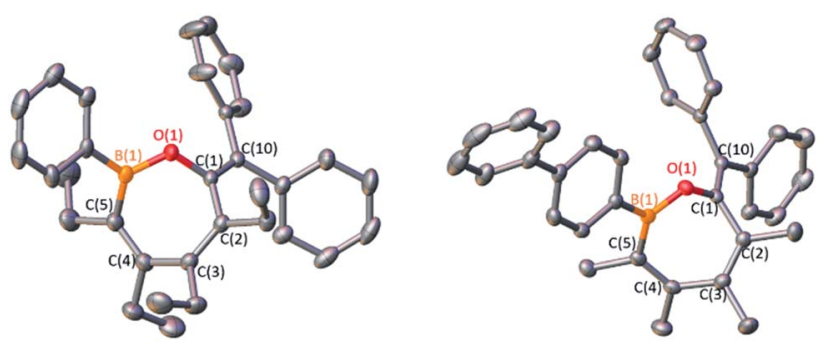

Fig. 6 (a) Solid-state structure of 6 (left) and 7 (right) hydrogen atoms are omitted for clarity and ellipsoids are depicted at the $50 \%$ probability level. Selected bond lengths $(A)$ for 6 : $B(1)-O(1)$ 1.368(2), $O(1)-C(1)$ 1.398(2), $C(1)-C(2) 1.489(2), C(2)-C(3) 1.351(2), C(3)-C(4) 1.500(2)$, $C(4)-C(5)$ 1.351(2), $C(5)-B(1)$ 1.561(1), $C(1)-C(10)$ 1.345(2); for 7: $B(1)-$ $\mathrm{O}(1) 1.372(2), \mathrm{O}(1)-C(1) 1.398(2), C(1)-C(2) 1.483(2), C(2)-C(3) 1.341(2)$, $C(3)-C(4) 1.482(2), C(4)-C(5) 1.355(2), C(5)-B(1) 1.563(2), C(1)-C(10)$ $1.340(2)$.

an X-ray diffraction structure that is similar to $\mathbf{C}_{2}$ with the notable feature of a $\mathrm{C}=\mathrm{C}$ bond coordinating to the bridgehead boron (Fig. 5). A ${ }^{13} \mathrm{C}$ DEPT experiment showed eight distinct resonances for both methylene and methyl groups indicating the presence of eight chemically inequivalent ethyl groups, consistent with the structure. The identity of 1-biphenyl dimer $\mathbf{E}_{2}$ was confirmed by multinuclear NMR spectroscopy and elemental analysis. The anticipated eight methyl signals were observed for $\mathbf{E}_{2}$ by ${ }^{1} \mathrm{H}$ NMR and ${ }^{13} \mathrm{C}$ NMR spectroscopy. Obtaining ${ }^{11} \mathrm{~B}$ NMR spectra for $\mathbf{D}_{2}$ and $\mathbf{E}_{2}$ revealed two resonances, one for the tricoordinate boron center and another for the pseudo-five coordinate bridgehead boron akin to $\mathbf{C}_{\mathbf{2}}\left(\mathbf{D}_{\mathbf{2}}=\right.$ 68.5, - 2.7 ppm; $\left.\mathbf{E}_{2}=70.4-5.8 \mathrm{ppm} ; c f . \mathbf{C}_{2}=69.8,-6.3 \mathrm{ppm}\right)$.

The 1,2-insertion reactions of borole dimers $\mathbf{D}_{\mathbf{2}}$ and $\mathbf{E}_{\mathbf{2}}$ with two equivalents of diphenylketene were investigated (Scheme 6). Upon heating the toluene- $d_{8}$ solutions to $100^{\circ} \mathrm{C}(1 \mathrm{~h}$ for $\mathbf{D}_{2}$ and $8 \mathrm{~h}$ for $\mathbf{E}_{2}$ ), ${ }^{1} \mathrm{H}$ and ${ }^{11} \mathrm{~B}$ NMR spectroscopy revealed the consumption of the borole dimers. The ${ }^{11} \mathrm{~B}$ signals at 43.7 and 44.9 ppm for the reactions with $\mathbf{D}_{2}$ and $\mathbf{E}_{2}$, respectively, are reminiscent of 4 (43.2 ppm). The reactions were scaled up and $\mathrm{X}$-ray diffraction studies confirmed the products from $\mathbf{D}_{\mathbf{2}}$ and $\mathbf{E}_{\mathbf{2}}$ as the seven-membered $\mathrm{BOC}_{5}$ rings 6 and 7, respectively (Fig. 6). The experiments confirm that insertion reactions are effective with other dimeric boroles although the reaction times differ. The reactions with the dimers featuring methyl groups on carbon were completed in $12 \mathrm{~h}\left(\mathbf{C}_{2}\right)$ and $8 \mathrm{~h}\left(\mathbf{E}_{2}\right)$ while the reaction with the dimer bearing ethyl groups on the carbon centers $\left(\mathbf{D}_{2}\right)$ was complete within an hour. ${ }^{17}$

\section{Conclusions}

In conclusion, we report the first examples of ring expansion reactions with borole dimers as precursors, specifically the 1,1insertion with elemental sulfur and an azide as well as the 1,2insertion with benzophenone and diphenylketene to access sixand seven-membered boracycles, respectively. The sulfur insertion product, a 1,2-thiaborine, could be coordinated to chromium in an $\eta^{6}$ fashion. It is notable that this complex could not be accessed from the peraryl-substituted monomeric 
borole products. An attempt to access an eight-membered ring was unsuccessful with 1,1-diphenylethylene oxide, instead forging a new $\mathrm{BOC}_{3}$ ring that is a component in effective pharmacophores. The reactions all required heat to crack the dimer but were all complete within $24 \mathrm{~h}$ at $100{ }^{\circ} \mathrm{C}$. Dimers with different substitution on boron and carbon are also capable of insertion reactions, exemplified in the reactions with diphenylketene. These studies solidify that bottleable monomeric boroles are not essential for insertion chemistry and that dimers have great potential to act as borole synthons to furnish a wealth of heterocycles with less restrictions on the substitution.

\section{Conflicts of interest}

There are no conflicts to declare.

\section{Acknowledgements}

We are grateful to the Welch Foundation (Grant No. AA-1846) and the National Science Foundation for a CAREER Award (Award No. 1753025) for their generous support of this work. We thank John R. Tidwell for assistance in X-ray diffraction analysis.

\section{Notes and references}

1 J. J. Eisch, N. K. Hota and S. Kozima, J. Am. Chem. Soc., 1969, 91, 4575-4577.

2 (a) H. Braunschweig and T. Kupfer, Chem. Commun., 2011, 47, 10903-10914; (b) H. Braunschweig, I. Fernández, G. Frenking and T. Kupfer, Angew. Chem., Int. Ed., 2008, 47, 1951-1954; (c) J. H. Barnard, S. Yruegas, K. Huang and C. D. Martin, Chem. Commun., 2016, 52, 9985-9991; (d) A. Steffen, R. M. Ward, W. D. Jones and T. B. Marder, Coord. Chem. Rev., 2010, 254, 1950-1976.

3 P. J. Fagan, E. G. Burns and J. C. Calabrese, J. Am. Chem. Soc., 1988, 110, 2979-2981.

4 (a) G. E. Herberich, B. Buller, B. Hessner and W. Oschmann, J. Organomet. Chem., 1980, 195, 253-259; (b) C. W. So, D. Watanabe, A. Wakamiya and S. Yamaguchi, Organometallics, 2008, 27, 3496-3501; (c) C. Sindlinger and P. N. Ruth, Angew. Chem., Int. Ed., 2019, 58, 15051-15056.

5 (a) C. Baldock, J. B. Rafferty, S. E. Sedelnikova, P. J. Baker, A. R. Stuitje, A. R. Slabas, T. R. Hawkes and D. W. Rice, Science, 1996, 274, 2107-2110; (b) L. J. Liu, A. J. V. Marwitz, B. W. Matthews and S. Y. Liu, Angew. Chem., Int. Ed., 2009, 48, 6817-6819; (c) D. H. Knack, J. L. Marshall, G. P. Harlow, A. Dudzik, M. Szaleniec, S. Y. Liu and J. Heider, Angew. Chem., Int. Ed., 2013, 52, 2599-2601; (d) S. Jinna and J. Finch, Drug Des. Dev. Ther., 2015, 9, 61856190; (e) A. S. Paller, W. L. Tom, M. G. Lebwohl, R. L. Blumenthal, M. Boguniewicz, R. S. Call, L. F. Eichenfield, D. W. Forsha, W. C. Rees, E. L. Simpson, M. C. Spellman, L. F. S. Gold, A. L. Zaenglein, M. H. Hughes, L. T. Zane and A. A. Hebert, J. Am. Acad. Dermatol., 2016, 75, 494-503.
6 (a) F. Jäkle, Chem. Rev., 2010, 110, 3985-4022; (b) E. Von Grotthuss, A. John, T. Kaese and M. Wagner, Asian J. Org. Chem., 2018, 7, 37-53; (c) A. Lorbach, A. Hubner and M. Wagner, Dalton Trans., 2012, 41, 6048-6063; (d) C. D. Entwistle and T. B. Marder, Angew. Chem., Int. Ed., 2002, 41, 2927-2931; (e) D. Frath, J. Massue, G. Ulrich and R. Ziessel, Angew. Chem., Int. Ed., 2014, 53, 2290-2310; (f) D. T. Yang, S. K. Mellerup, J. B. Peng, X. Wang, Q. S. Li and S. N. Wang, J. Am. Chem. Soc., 2016, 138, 11513-11516; $(g)$ F. Vidal and F. Jäkle, Angew. Chem., Int. Ed., 2019, 58, 58465870; (h) F. Jäkle, Coord. Chem. Rev., 2006, 250, 1107-1121.

7 (a) Z. F. Xi, Acc. Chem. Res., 2010, 43, 1342-1351; (b) Z. Zhang, R. M. Edkins, M. Haehnel, M. Wehner, A. Eichhorn, L. Mailänder, M. Meier, J. Brand, F. Brede, K. MüllerBuschbaum, H. Braunschweig and T. B. Marder, Chem. Sci., 2015, 6, 5922-5927; (c) T. Heitkemper and C. P. Sindlinger, Chem.-Eur. J., 2019, 25, 6628-6637.

8 (a) G. E. Herberich, B. Buller, B. Hessner and W. Oschmann, J. Organomet. Chem., 1980, 195, 253-259; (b) X. Y. Yan and C. J. Xi, Acc. Chem. Res., 2015, 48, 935-946.

9 (a) S. Yruegas, C. Wilson, J. L. Dutton and C. D. Martin, Organometallics, 2017, 36, 2581-2587; (b) H. Braunschweig, F. Hupp, I. Krummenacher, L. Mailänder and F. Rauch, Chem.-Eur. J., 2015, 21, 17844-17849; (c) A. Fukazawa, J. L. Dutton, C. Fan, L. G. Mercier, A. Y. Houghton, Q. Wu, W. E. Piers and M. Parvez, Chem. Sci., 2012, 3, 1814-1818; (d) K. Huang, S. A. Couchman, D. J. Wilson, J. L. Dutton and C. D. Martin, Inorg. Chem., 2015, 54, 8957-8968; (e) K. Huang and C. D. Martin, Inorg. Chem., 2015, 54, 18691875; (f) Y. T. Su and R. Kinjo, Chem. Soc. Rev., 2019, 48, 3613-3659.

10 (a) T. Heitkemper and C. P. Sindlinger, Chem.-Eur. J., 2019, 25, 6628-6637; (b) Z. L. Zhang, R. M. Edkins, M. Haehnel, M. Wehner, A. Eichhorn, L. Mailänder, M. Meier, J. Brand, F. Brede, K. Müller-Buschbaum, H. Braunschweig and T. B. Marder, Chem. Sci., 2015, 6, 5922-5927.

11 (a) H. Braunschweig, C. W. Chiu, A. Damme, K. Ferkinghoff, K. Kraft, K. Radacki and J. Wahler, Organometallics, 2011, 30, 3210-3216; (b) H. Braunschweig, C. W. Chiu, J. Wahler, K. Radacki and T. Kupfer, Chem.-Eur. J., 2010, 16, 1222912233; (c) Z. L. Zhang, Z. Wang, M. Haehnel, A. Eichhorn, R. M. Edkins, A. Steffen, A. Krueger, Z. Y. Lin and T. B. Marder, Chem. Commun., 2016, 52, 9707-9710; (d) Z. Wang, Y. Zhou, K. H. Lee, W. H. Lam, R. D. Dewhurst, H. Braunschweig, T. B. Marder and Z. Y. Lin, Chem.-Eur. J., 2017, 23, 11587-11597.

12 (a) P. J. Fagan, W. A. Nugent and J. C. Calabrese, J. Am. Chem. Soc., 1994, 116, 1880-1889; (b) G. E. Herberich and H. Ohst, Chem. Ber., 1985, 118, 4303-4313.

13 J. J. Baker, K. H. M. Al Furaiji, O. T. Liyanage, D. J. D. Wilson, J. L. Dutton and C. D. Martin, Chem.-Eur. J., 2019, 25, 15811587.

14 (a) G. E. Herberich, B. Hessner, H. Ohst and I. A. Raap, J. Organomet. Chem., 1988, 348, 305-316; (b) G. E. Herberich, M. Negele and H. Ohst, Chem. Ber., 1991, 124, 25-29.

15 (a) M. J. D. Bosdet and W. E. Piers, Can. J. Chem., 2009, 87, 829; (b) P. G. Campbell, A. J. V. Marwitz and S. Y. Liu, Angew. 
Chem., Int. Ed., 2012, 51, 6074-6092; (c) E. R. Abbey, A. N. Lamm, A. W. Baggett, L. N. Zakharov and S. Y. Liu, J. Am. Chem. Soc., 2013, 135, 12908-12913; (d) H. Braunschweig, K. Geetharani, J. O. C. Jimenez-Halla and M. Schafer, Angew. Chem., Int. Ed., 2014, 53, 35003504; (e) J. H. Chen, Z. Bajko, J. W. Kampf and A. J. Ashe III, Organometallics, 2007, 26, 1563-1564; (f) A. D. Rohr, M. M. B. Holl, J. W. Kampf and A. J. Ashe III, Organometallics, 2011, 30, 3698-3700; $(g)$ B. Su and R. Kinjo, Synthesis, 2017, 49, 2985-3034; (h) P. A. Brown, C. D. Martin and K. L. Shuford, Phys. Chem. Chem. Phys., 2019, 21, 18458-18466; (i) B. L. Wang, Y. X. Li, R. Ganguly, H. Hirao and R. Kinjo, Nat. Commun., 2016, 7; (j) B. L. Wang and R. Kinjo, Chem. Sci., 2019, 10, 2088-2092; (k) A. W. Baggett, F. Guo, B. Li, S. Y. Liu and F. Jäkle, Angew. Chem., Int. Ed., 2015, 54, 11191-11195.

16 (a) J. H. Barnard, P. A. Brown, K. L. Shuford and C. D. Martin, Angew. Chem., Int. Ed., 2015, 54, 12083-12086; (b) S. Yruegas, D. C. Patterson and C. D. Martin, Chem. Commun., 2016, 52, 6658-6661; (c) S. Yruegas and C. D. Martin, Chem.-Eur. J., 2016, 22, 18358-18361; (d) H. Braunschweig, C. Hörl, L. Mailänder, K. Radacki and J. Wahler, Chem.-Eur. J., 2014, 20, 9858-9861; (e) S. A. Couchman, T. K. Thompson, D. J. Wilson, J. L. Dutton and C. D. Martin, Chem. Commun., 2014, 50, 11724-11726; (f) H. Braunschweig, M. A. Celik, F. Hupp, I. Krummenacher and L. Mailänder, Angew. Chem., Int. Ed., 2015, 54, 6347-6351; (g) H. Braunschweig, M. A. Celik, T. Dellermann, G. Frenking, K. Hammond, F. Hupp, H. Kelch, I. Krummenacher, F. Lindl and L. Mailänder, Chem.-Eur. J., 2017, 23, 80068013.

17 In an attempt to observe monomeric species, conducting elevated temperature ${ }^{1} \mathrm{H}$ and ${ }^{11} \mathrm{~B}$ NMR spectroscopic experiments on $\mathbf{C}_{2}$ and $\mathbf{E}_{2}$ in toluene- $d_{8}$ to $80^{\circ} \mathrm{C}$ did not show any change in speciation (Fig. S102, S103 and S106, S107 $\dagger$ ). Given the observed reaction times, this equilibrium is presumably shifted towards the dimer. NMR spectroscopic studies on $\mathbf{D}_{2}$ revealed new ${ }^{1} \mathrm{H}$ resonances in the aryl region that emerged at $45{ }^{\circ} \mathrm{C}$ and temperatures above. Although no corresponding new ${ }^{11} \mathrm{~B}$ NMR resonance could be detected, it is possible that the new species detected by ${ }^{1} \mathrm{H}$ NMR spectroscopy could be monomeric borole D (Fig. S104†).

18 (a) P. J. Grisdale and J. L. Williams, J. Org. Chem., 1969, 34, 1675-1677; (b) F. A. Davis and M. J. S. Dewar, J. Am. Chem. Soc., 1968, 90, 3511-3515.

19 (a) A. J. Ashe III, X. D. Fang, X. G. Fang and J. W. Kampf, Organometallics, 2001, 20, 5413-5418; (b) J. Pan, J. W. Kampf and A. J. Ashe III, Organometallics, 2006, 25, 197-202; (c) J. Pan, J. Wang, M. M. B. Holl, J. W. Kampf and A. J. Ashe III, Organometallics, 2006, 25, 3463-3467; (d) J. Pan, J. W. Kampf and A. J. Ashe III, Organometallics, 2009, 28, 506-511.

20 F. A. Tsao and D. W. Stephan, Chem. Commun., 2017, 53, 6311-6314.

21 B. Mailvaganam, B. G. Sayer and M. J. Mcglinchey, J. Organomet. Chem., 1990, 395, 177-185.

22 G. Klopman and K. Noack, Inorg. Chem., 1968, 7, 579-584. 23 (a) Y. K. Loh, C. C. Chong, R. Ganguly, Y. X. Li, D. Vidovic and R. Kinjo, Chem. Commun., 2014, 50, 8561-8564; (b) L. E. Laperriere, S. Yruegas and C. D. Martin, Tetrahedron, 2019, 75, 937-943; (c) J. N. Bentley and C. B. Caputo, Tetrahedron, 2019, 75, 31-35.

24 (a) H. Braunschweig, A. Damme, C. Hörl, T. Kupfer and J. Wahler, Organometallics, 2013, 32, 6800-6803; (b) S. Yruegas, K. Huang, D. J. Wilson, J. L. Dutton and C. D. Martin, Dalton Trans., 2016, 45, 9902-9911; (c) B. C. Caputo, Z. J. Manning, J. H. Barnard and C. D. Martin, Polyhedron, 2016, 114, 273-277; (d) V. A. K. Adiraju and C. D. Martin, Dalton Trans., 2017, 46, 10324-10331; (e) H. Braunschweig, M. Domling, S. Kachel, H. Kelch, T. Kramer, I. Krummenacher, C. Lenczyk, S. J. Lin, Z. Y. Lin, C. Possiel and K. Radacki, Chem.-Eur. J., 2017, 23, 16167-16170; (f) C. Fan, L. G. Mercier, W. E. Piers, H. M. Tuononen and M. Parvez, J. Am. Chem. Soc., 2010, 132, 9604-9606; (g) A. Y. Houghton, V. A. Karttunen, C. Fan, W. E. Piers and H. M. Tuononen, J. Am. Chem. Soc., 2013, 135, 941-947.

25 It is unclear with the experimental data whether the product is dictated by kinetics or thermodynamics.

26 H. Braunschweig, I. Krummenacher, L. Mailänder and F. Rauch, Chem. Commun., 2015, 51, 14513-14515. 